\title{
ADMINISTRASI KEUANGAN SEKOLAH
}

\author{
Nofita Sari \\ E-mail
}

nofitasari91199@gmail.com

Universitas Negeri Padang

\begin{abstract}
ABSTRAK
Administrasi merupakan kegiatan penyusunan dan pencatatan data atau informasi secara sistematis. Tujuan dari administrasi adalah menyediakan keterangan serta memudahkan dalam hubungannya satu sama lain sehingga dapat mencapai tujuan secara efektif dan efisien. Segala kegiatan yang berlangsung di dalam suatu usaha atau perusahaan baik itu manufaktur, dagang maupun jasa selalu ada hubungannya dengan administrasi keuangan. Dengan administrasi keuangan yang dilakukan secara terus menerus dapat diketahui seberapa besar jumlah pengeluaran dan pendapatan perusahaan agar biaya yang dikeluarkan efisien. Dengan demikian proses administrasi keuanagn di sekolah berjalan dengan baik.
\end{abstract}

Kata kunci : Administrasi, Keuangan,

\section{PENDAHULUAN}

Dengan berkembangnya dunia pendidikan, tentu diperlukannya atau harus memperhatikan pengaturan strategi administrasi keuangan yang tepat. Administrasi keuangan merupakan salah satu aspek penting bagi pendidikan untuk dapat mengatur pendapatan maupun pengeluaran suatu pendidikan. Oleh karena itu pendidikan dalam melakukan kegiatan administrasi keuangannya haruslah dilakukan secara efektif dan efisien.
Dengan memperhatikan berbagai kemungkinan yang ada dan dihubungkan dengan keuangan, maka diperlukannya suatu administrasi kauangan. Oleh karena itu diperlukan suatu proses administrasi yang dapat membantu pendidikan dalam mengelola keuangan.

A. PENGERTIAN ADMINISTRASI KEUANGAN SEKOLAH

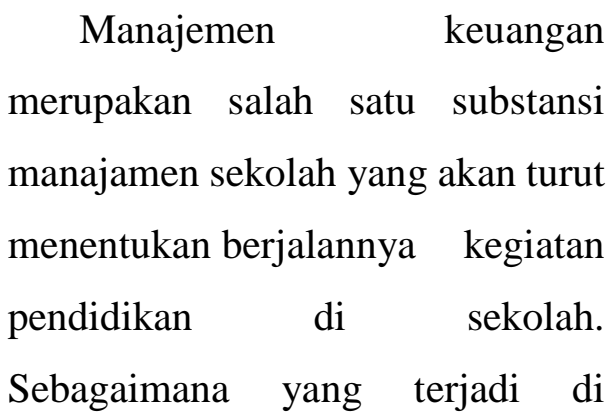




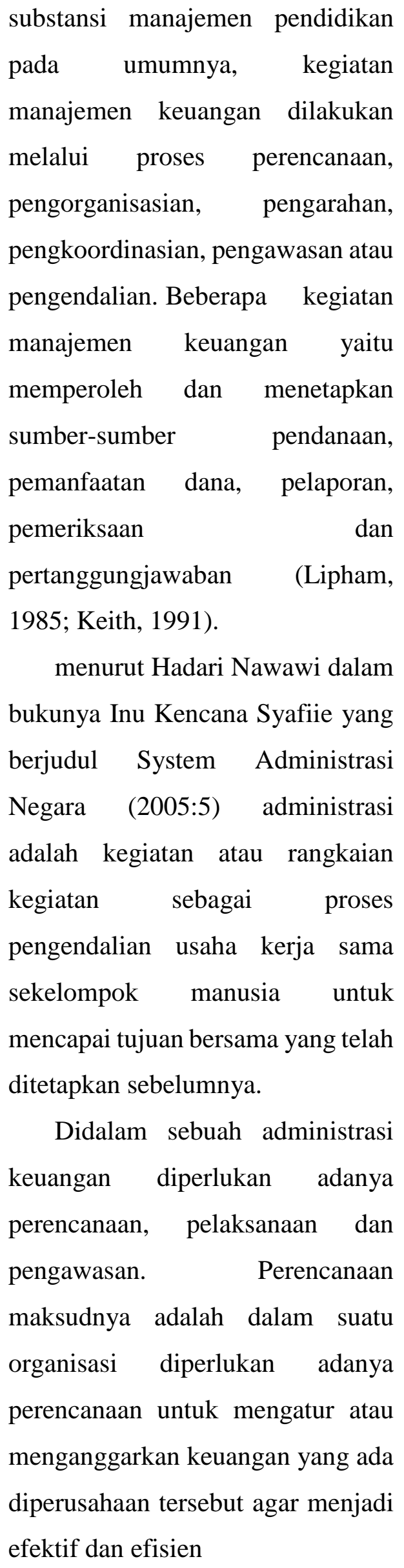

substansi manajemen pendidikan pada umumnya, kegiatan

B. PROSES

ADMINISTRASI KEUANGAN

1. Perencanaan Keuangan Sekolah

Rencana anggaran pendapatan dan belanja sekolah (RAPBS) pada dasarnya memuat tentang berbagai program dan kegiatan yang akan dilaksanakan sekolah, untuk membiayai program tersebut selam 1 tahun anggaran. Penyusunan RAPBS dapat menempuh beberapa langkah. Sutisna 1989 menyatakan langkah dimaksud sebagai berikut:

1. Penetapan Tujuan, perumusan tujuan adalah suatu keharusan dalam penyusunan anggaran yang efektif.

2. Penjabaran tujuan kedalam program pendidikan.

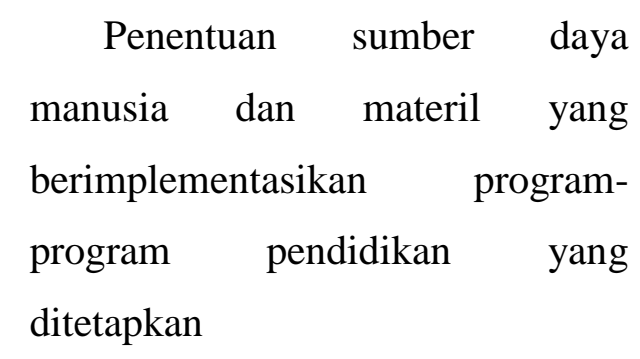

2. Pengelolaan Dan Penggunaan Keuangan Sekolah

Pengelolaan akan dianggap efektif apabila merujuk pada Rencana Anggaran Pendapatan dan Belanja Sekolah (RAPBS) untuk satu tahun pelajaran, para kepala 
sekolah bersama smua pemegang peran di sekolah pada umumnya menempuh langkah-langkah sebagai berikut :

1. Merancang suatu program sekolah yang ideal untuk mencapai tujuan yang diinginkan pada tahun pelajaran yang bersangkutan.

2. Melakukan inventarisasi semua kegiatan dan menghitung perkiraan kebutuhan dana penunjang.

3. Melakukan peninjauan ulang atas program awal berdasarkan kemungkinan tersedianya dana pendukung yang dapat dihimpun.

4. Menetapkan prioritas kegiatan yang akan dilaksanakan pada tahun pelajaran yang bersangkutan.

5. Melakukan perhitungan rinci pemanfaatan dana yang tersedia untuk masing-masing kegiatan (Depdiknas, 2000 : 178 - 179)

6. Menuangkan perhitunganperhitungan rinci tersebut ke dalam suatu format yang telah disepakati untuk digunakan oleh setiap sekolah.

7. Pengesahan dokumen RAPBS oleh instansi yang berwenang

3. Proses pengelolaan keuangan di sekolah meliputi:

1. Perencanaan anggaran
2. Strategi mencari sumber dana sekolah

3. Penggunaan keuangan sekolah

4. Pengawasan dan evaluasi anggaran

5. Pertanggungjawaban

Menurut Lipham (1985), ada empat fase penyusunan anggaran antara lain:

1. Merencanakan anggaran

2. Mempersiapkan anggaran

3. Mengelola pelaksanaan anggaran

4. Menilai pelaksanaan anggaran

Anggaran mempunyai fungsi:

1. Sebagai alat penaksir

2. Sebagai alat otorisasi

3. Sebagai alat efisiensi

Pemasukan dan pengeluaran keuangan sekolah diatur dalam Rancangan Anggaran Pendapatan dan Belanja Sekolah (RAPBS). Ada beberapa hal yang berhubungan dengan penyusunan RAPBS, antara lain:

1. Penerimaan

2. Penggunaan

3. Pertanggungjawaban

4.Pertanggung jawaban keuangan sekolah

Pertanggung jawaban dapat disampaikan pada pimpinan, sumber pemberi dana maupun kepada personil 
sekolah untuk dapat diketahui bersama. Hal ini perlu dilakukan mengingat “ keuangan " merupakan hal yang sangat sensitif. Ketidakjelasan laporan pertanggung jawaban keuangan sekolah akan menambah anggapan negatif terhadap kepala sekolah dalam hal penyelenggaraan keuangan sekolah yang tidak tertib.

C. PERANAN GURU DALAM KEUANGAN SEKOLAH

Beberapa peran guru dalam administrasi keuangan ini meliputi:

1. Membuat file keuangan sesuai dengan dana pembangunan.

2. Membuat laporan data usulan pembayaran gaji, rapel ke Pemerintah Kota.

3. Membuat pembukuan penerimaan dan penggunaan dana pembangunan.

4. Membuat laporan dana pembangunan pada akhir tahun anggaran.
5. Membuat laporan Rancangan Anggaran Pendapatan Bantuan Sekolah( RAPBS ).

6. Membuat laporan triwulan dana Bantuan Operasional Sekolah ( BOS ).

7. Menyetorkan pajak PPN dan PPh.

8. Membagikan gaji atau rapel.

9. Menyimpan dan membuat arsip peraturan keuangan sekolah.

Daftar pustaka

http://masykurpijay.blogspot.com/2011/01 /administrasi-keuangan-sekolah-

hubungan.html. diakses tanggal 13 oktober 2016.

Purwanto, M. Ngalim. 1990. AdministrasidanSupervisiPendidikan .

Bandung: PT Remaja Rosdakarya

Nawawi, H., Inu Kencana Syafiie, Jakarta 2005 